\title{
The Nature of the Carbon Dioxide Titration Curve in the Normal Dog*
}

\author{
Jordan J. Cohen, $\dagger$ Newton C. Brackett, Jr., $\nmid$ and William B. Schwartz \\ (From the Department of Medicine, Tufts University School of Medicine, and the Renal \\ Laboratory, Pratt Clinic-New England Center Hospital, Boston, Mass.)
}

Previous studies have demonstrated that the abrupt rise in bicarbonate concentration of the extracellular fluid induced by acute hypercapnia depends on body buffering rather than on augmented renal acid excretion $(1,2)$. These observations were carried out in animals exposed to only a single concentration of carbon dioxide, and the quantitative aspects of the response to varying degrees of hypercapnia have received relatively little attention (3-5).

The present study was undertaken to define the whole body titration curve ${ }^{1}$ of unanesthetized dogs during acute steady-state exposure to carbon dioxide in concentrations ranging from 7 to $18 \%$. The data demonstrate that the largest rise in bicarbonate concentration occurs with moderate degrees of hypercapnia, the increment in bicarbonate diminishing with each successive increment in $\mathrm{PCO}_{2}$. By contrast, changes in extracellular hydrogen ion concentration are directly proportional to changes in $\mathrm{PcO}_{2}$ over a range of 30 to $140 \mathrm{~mm}$ Hg.

\section{Methods}

Twenty-one experiments were performed in twentyone unanesthetized female mongrel dogs ranging in weight between 12 and $21 \mathrm{~kg}$. The animals were studied at various levels of carbon dioxide tension in a $15-\times 20$-foot environmental chamber that will be described in detail elsewhere (6). In general, the chamber allows main-

* Submitted for publication October 14, 1963; accepted December 19, 1963.

Supported in part by grants from the National Heart Institute, National Institutes of Health, U. S. Public Health Service (H-759 and HTS 5309), and the Life Insurance Medical Research Fund.

† Work done during tenure of a postdoctoral research fellowship of the American Heart Association.

${ }^{1} \mathrm{By}$ carbon dioxide "titration curve" we mean the relation between $\mathrm{PCO}_{2}$ and plasma bicarbonate (or $\mathrm{H}^{+}$concentration) when the partial pressure of carbon dioxide is systematically varied and the intact organism is allowed to reach an acute steady state. tenance of a constant ambient carbon dioxide concentration at any desired level up to $20 \%$. Through a feedback control system, the carbon dioxide level can be held within a range of approximately $\pm 0.5 \%$ of the desired level. A circulating fan provides uniform distribution of gases. Calibration of the controlling apparatus was verified by frequent analysis of gas samples obtained from the chamber with a Scholander volumetric gas analyzer. Partial pressure of oxygen, monitored by a Beckman infrared oxygen analyzer, was maintained by manual control between 140 and $160 \mathrm{~mm} \mathrm{Hg}$. The investigators, entering the chamber through an air lock, wore masks and breathed from a self-contained compressed air apparatus that prevented alteration of the atmosphere to which the dogs were exposed.

The animals remained within the carbon dioxide environment throughout the course of the experiment. Heparinized blood was drawn anaerobically from the femoral artery by percutaneous puncture or inlying polyethylene catheter. Urine was collected under mineral oil through an indwelling Foley catheter; the bladder was emptied by manual compression and aspiration. Food and water were withheld throughout the experimental day.

Preliminary plateau studies. Seventeen preliminary experiments were performed in twelve animals to determine the length of time required to approximate an acute steady state of acid-base equilibrium after exposure to various levels of carbon dioxide. Each animal was abruptly exposed to one level of carbon dioxide, which was then held constant for 6 hours. Four studies were done at 6 to $8 \%$, eight at 10 to $12 \%$, and five at $18 \%$ carbon dioxide. No animal was exposed to any given level on more than one occasion. One or two control blood samples were obtained in the hour preceding the experiment. Blood samples were drawn at 1, 2, 4, and 6 hours after exposure.

The data for the preliminary studies are shown in Table I. For any single level of inspired carbon dioxide, the plasma bicarbonate concentration could not be shown to change significantly after 1 hour. When pooled data from all experiments are analyzed, however, the findings are somewhat different. Although the 2-hour bicarbonate concentration is still not significantly different from the 1-hour value, the 4- and 6-hour values show a significant increase $(p<0.01)$, averaging $1.3 \mathrm{mEq}$ per $L$. Part of this rise can probably be attributed to a significant increase in arterial $\mathrm{PCO}_{2}$ (average, $14 \mathrm{~mm} \mathrm{Hg}$ ) observed at both 4 and 6 hours in the $18 \%$ group; the in- 


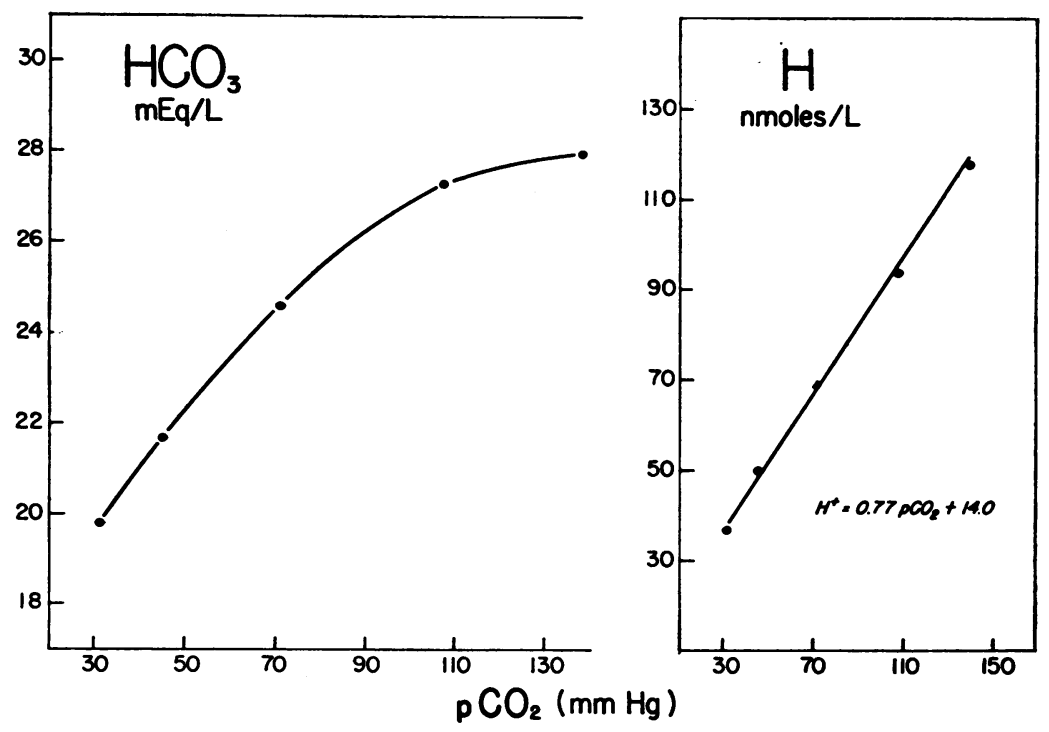

Fig. 1. Relationship of $\mathrm{PCO}_{2}$ to Plasma bicarbonate and hydrogen ION CONCENTRATIONS FOR THE "UPGOING" STUDIES. The curve relating bicarbonate to $\mathrm{PCO}_{2}$ is drawn by inspection through the average bicarbonate values for the $7-11-18 \%$ and $11-15-18 \%$ (upgoing) experiments. The line defining the relationships between hydrogen ion concentration and $\mathrm{PCO}_{2}$ was calculated by averaging the weighted regression lines from the "upgoing" experiments. (nmoles $=$ nanomoles, $10^{-9}$ moles.)

crease in $\mathrm{PCO}_{2}$ in the face of a nearly constant tension of inspired carbon dioxide is presumably accounted for by the progressive fatigue resulting from the intense respiratory effort.

Experimental design. Twenty-one dogs were exposed for a 2-hour period at each of three successive levels of carbon dioxide. Seven experiments were done in each of the following sequences : a) $7,11,18 \%$; b) $11,15,18 \%$. As a control for the rise that might occur from 6 hours of total exposure (vide supra), a "reverse" protocol was carried out in seven animals in which the sequence of exposure was c) $18,11,7 \%$. The transition between carbon dioxide levels was accomplished within 2 to 3 minutes.

Two control blood samples were obtained in the hour immediately preceding exposure to carbon dioxide and 1, $1 \frac{1}{2}$, and 2 hours after each abrupt change in concentra- tion of inspired carbon dioxide. After the animals had been returned to room air, additional blood samples were obtained from all seven dogs in group c. The bladder was emptied immediately before exposure to carbon dioxide, and urine was collected thereafter at the 2 -hour intervals corresponding to the carbon dioxide periods. Successive collections were pooled when the urine volume was less than $10 \mathrm{ml}$ per period.

Analytical methods. Urine and blood $\mathrm{pH}$ were determined anaerobically at $37^{\circ} \mathrm{C}$ with an Epsco blood parameter analyzer using the Metrohm capillary $\mathrm{pH}$ electrode. Urine and plasma chloride concentrations were measured in the early studies by titration with silver nitrate using a potentiometric method (7) and in later studies with the Cotlove-Aminco chloridometer. Whole blood lactate was determined by the method of Barker and Summerson (8) and pyruvate by the technique of Friedmann

TABLE I

Changes in plasma bicarbonate concentration during preliminary plateau experiments

\begin{tabular}{ccccccr}
\hline \hline & \multirow{5}{c}{$\begin{array}{c}\text { No. of } \\
\mathrm{CO}_{2}\end{array}$} & \multicolumn{4}{c}{ Bicarbonate concentration } \\
\cline { 3 - 7 } & experiments & Control & 1 Hour & 2 Hour & 4 Hour & 6 Hour \\
\hline$\%$ & & & & $m E q / L$ & & \\
$6-8$ & 4 & $18.5 \pm 0.9^{*}$ & $21.7 \pm 1.1$ & $21.7 \pm 0.9$ & $21.9 \pm 1.3$ & $22.7 \pm 1.2$ \\
$10-12$ & 8 & $20.3 \pm 0.9$ & $24.4 \pm 0.6$ & $25.2 \pm 0.6$ & $26.3 \pm 0.5$ & $25.8 \pm 0.4$ \\
18 & 5 & $20.4 \pm 0.5$ & $26.7 \pm 0.7$ & $26.3 \pm 1.0$ & $28.0 \pm 1.0$ & $28.2 \pm 1.0$
\end{tabular}

$*$ Mean $\pm \mathrm{SE}$. 
TABLE II

Acid-base parameters of plasma during titration of the dog with carbon dioxide*

\begin{tabular}{|c|c|c|c|c|c|c|c|c|c|c|c|c|}
\hline Experiment no. & $\mathrm{PcO}_{2}$ & $\mathbf{H}^{+}$ & $\mathrm{HCO}_{3}^{-}$ & $\mathrm{PcO}_{2}$ & $\mathbf{H}^{+}$ & $\mathrm{HCO}_{3}^{-}$ & $\mathrm{PcO}_{2}$ & $\mathbf{H}^{+}$ & $\mathrm{HCO}_{3}-$ & $\mathrm{PcO}_{2}$ & $\mathbf{H}^{+}$ & $\mathrm{HCO}_{3}-$ \\
\hline A. Upgoing $7-11-18 \%$ & $m m \mathrm{Hg} n$ & $\begin{array}{c}\text { nmoles } / L \dagger \\
\text { Control }\end{array}$ & $\lceil m E q / L$ & $m m \mathrm{Hg}$ & $\begin{array}{c}n \text { moles } / L n \\
7 \% \mathrm{CO}_{2}\end{array}$ & $m E q^{\prime} L$ & $m m H g$ & $\begin{array}{l}\text { moles } / L \\
11 \% \mathrm{CO}_{2}\end{array}$ & $m E q / L$ & $m m H g$ & \multicolumn{2}{|c|}{$18 \% \mathrm{CO}_{2}$} \\
\hline 1 & 29 & 33 & 20.6 & 47 & 51 & 22.4 & 73 & 68 & 25.5 & 132 & 118 & 26.9 \\
\hline 2 & 33 & 38 & 20.2 & 44 & 48 & 21.9 & 73 & 69 & 25.1 & 140 & 122 & 27.5 \\
\hline 3 & 35 & 43 & 19.4 & 48 & 54 & 21.0 & 73 & 73 & 23.8 & 132 & 117 & 26.9 \\
\hline 4 & 29 & 39 & 17.5 & 43 & 54 & 19.2 & 67 & 75 & 21.2 & 139 & 139 & 23.8 \\
\hline 5 & 29 & 35 & 19.3 & 44 & 50 & 20.8 & 70 & 70 & 23.6 & 131 & 116 & 27.1 \\
\hline 6 & 32 & 38 & 20.5 & 45 & 48 & 22.7 & 71 & 65 & 26.4 & 116 & 102 & 27.3 \\
\hline 7 & 32 & 36 & 21.5 & 46 & 47 & 23.6 & 72 & 66 & 26.2 & 138 & 109 & 30.3 \\
\hline B. Upgoing 11-15-18\% & \multicolumn{3}{|c|}{ Control } & \multicolumn{3}{|c|}{$11 \% \mathrm{CO}_{2}$} & \multicolumn{3}{|c|}{$15 \% \mathrm{CO}_{2}$} & \multicolumn{3}{|c|}{$18 \% \mathrm{CO}=$} \\
\hline 8 & 33 & 38 & 21.0 & 73 & 66 & 26.5 & 111 & 87 & 30.6 & 142 & 105 & 32.5 \\
\hline 9 & 32 & 36 & 21.2 & 69 & 69 & 24.2 & 99 & 89 & 26.5 & 122 & 102 & 28.4 \\
\hline 10 & 29 & 38 & 18.6 & 65 & 64 & 24.6 & 101 & 89 & 27.0 & 139 & 117 & 28.4 \\
\hline 11 & 29 & 35 & 20.1 & 70 & 70 & 23.7 & 110 & 98 & 26.8 & 145 & 121 & 28.6 \\
\hline 12 & 29 & 41 & 17.1 & 76 & 76 & 23.7 & 115 & 106 & 25.8 & 153 & 143 & 25.5 \\
\hline 13 & 28 & 35 & 19.5 & 76 & 75 & 24.1 & 107 & 97 & 26.4 & 142 & 120 & 28.2 \\
\hline 14 & 30 & 36 & 19.8 & 69 & 64 & 25.6 & 104 & 89 & 28.0 & 148 & 118 & 29.9 \\
\hline C. Reverse 18-11-7\% & \multicolumn{3}{|c|}{ Control } & \multicolumn{3}{|c|}{$18 \% \mathrm{CO}_{2}$} & \multicolumn{3}{|c|}{$11 \% \mathrm{CO}_{2}$} & \multicolumn{3}{|c|}{$7 \% \mathrm{CO}_{2}$} \\
\hline 15 & 28 & 33 & 20.5 & 127 & 116 & 26.3 & 73 & 66 & 26.3 & 50 & 47 & 25.4 \\
\hline 16 & 30 & 35 & 20.7 & 130 & 114 & 27.1 & 76 & 69 & 26.4 & 50 & 49 & 24.8 \\
\hline 17 & 34 & 39 & 20.9 & 136 & 125 & 26.0 & 80 & 73 & 26.2 & 53 & 50 & 25.2 \\
\hline 18 & 37 & 36 & 24.3 & 134 & 108 & 29.8 & 82 & 69 & 28.5 & 51 & 49 & 25.4 \\
\hline 19 & 31 & 38 & 19.4 & 127 & 112 & 27.0 & 74 & 72 & 24.6 & 52 & 55 & 22.6 \\
\hline 20 & 33 & 36 & 21.7 & 127 & 108 & 28.1 & 74 & 66 & 26.9 & 50 & 49 & 24.6 \\
\hline 21 & 32 & 36 & 21.8 & 134 & 115 & 27.9 & 76 & 67 & 27.0 & 51 & 49 & 24.9 \\
\hline
\end{tabular}

* The values shown in the table represent the average of the three observations for each experimental period and the two observations during each control period.

$t$ nmoles $=$ nanomoles $\left(10^{-\rightarrow}\right.$ moles $)$.

and Haugen (9) as modified by Huckabee. Total serum protein was measured by the biuret method (10), and albumin was measured by sodium sulfite precipitation (11). Sodium and potassium determinations were carried out on the Technicon autoanalyzer. Plasma water concentration was determined by the osmometric method (12). Extracellular fluid volume was estimated from chloride space utilizing a correction for the intracellular chloride shifts induced by hypercapnia (1). The remainder of the techniques have been described previously (13).

For comparison of the behavior of blood in vitro with that of blood in the intact animal, eleven arterial blood samples from eight dogs were titrated with carbon dioxide. Equilibrium with $\mathrm{CO}_{2}-\mathrm{O}_{2}$ gas mixtures and $\mathrm{pH}$ determinations were performed with Astrup micro equipment ${ }^{2}$ (14).

\section{Results}

The plasma values shown in Table II and Figures 1 to 3 represent the average of the three observations made during each experimental period. The data from the 7-11-18\% and $11-15-18 \%$ protocols ("upgoing") in which stepwise increases in $\mathrm{PCO}_{2}$ were studied are combined, since there was

\footnotetext{
2 Type AMD-1, Radiometer Corp., Copenhagen, Denmark.
}

no significant difference between the average plasma bicarbonate concentrations and hydrogen ion concentrations at comparable values for $\mathrm{PCO}_{2}$. On the left-hand side of Figure 1 are shown the mean plasma bicarbonate values for all upgoing experiments. The average control bicarbonate was $19.8 \mathrm{mEq}$ per $\mathrm{L}$. The bicarbonate level rose significantly with each increment of $\mathrm{PCO}_{2}$, reaching a final average value of $28.0 \mathrm{mEq}$ per $\mathrm{L}$ at an inspired concentration of $18 \% \mathrm{CO}_{2}$. Approximately two-thirds of the rise in bicarbonate concentration occurred with less than half of the total increment in $\mathrm{PCO}_{2}$. Comparable data for the reverse experiments $(18-11-7 \%)$ are shown on the left-hand side of Figure 2. The average control bicarbonate concentration was $21.3 \mathrm{mEq}$ per $\mathrm{L}$ and rose to $27.5 \mathrm{mEq}$ per $\mathrm{L}$ during exposure to $18 \%$ carbon dioxide. Stepwise decrements in inspired carbon dioxide were followed by reductions in bicarbonate concentrations to 26.6 and 24.7 $\mathrm{mEq}$ per $\mathrm{L}$ at 11 and $7 \% \mathrm{CO}_{2}$, respectively. After the animals were returned to room air, the average plasma bicarbonate concentration fell to $21.4 \mathrm{mEq}$ per $\mathrm{L}$ and $\mathrm{PCO}_{2}$ to $33 \mathrm{~mm} \mathrm{Hg}$, values not significantly different from control. 


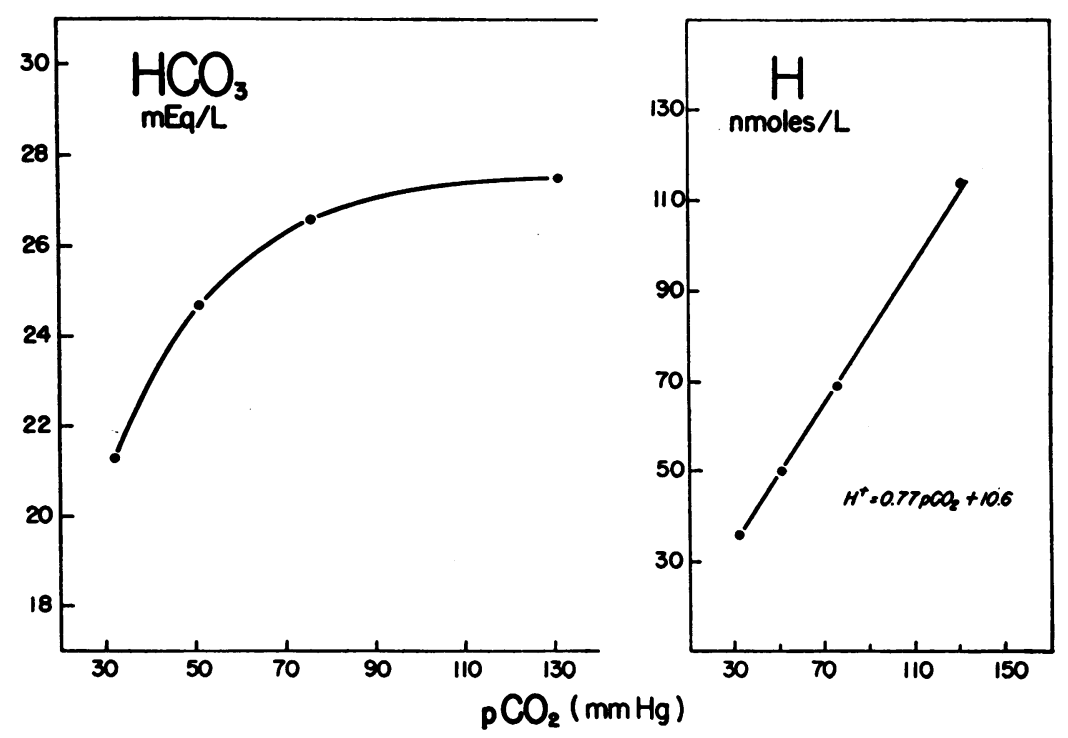

Fig. 2. Relationship of $\mathrm{PCO}_{2}$ to Plasma bicarbonate and hydrogen ion CONCENTRATIONS FOR THE "REVERSE" STUDies. The curve relating bicarbonate to $\mathrm{PCO}_{2}$ is drawn by inspection through the average values for the $18-11-7 \%$ (reverse) experiments. The line defining the relationship between the hydrogen ion concentration and $\mathrm{PCO}_{2}$ was obtained by averaging the weighted regression lines from the "reverse" experiments.

It is apparent from a comparison of Figures 1 and 2 that the shape of the bicarbonate curves for both protocols is similar. At the control and at the $18 \%$ carbon dioxide points, there was no significant difference between plasma bicarbonate concentration in the upgoing and reverse groups. The bicarbonate levels did appear to be somewhat higher at the intermediate points in the reverse protocol, but this difference could not be statistically analyzed because the average $\mathrm{PcO}_{2}$ observed in the upgoing and reverse protocols at the same level of inspired carbon dioxide were significantly different $(\mathrm{p}<0.01)$. This difference in arterial $\mathrm{PCO}_{2}$ was presumably the result of a different ventilatory response to comparable ambient concentrations of carbon dioxide. ${ }^{3}$

Figure 3 shows the relationship between hydrogen ion concentration and $\mathrm{Pco}_{2}$ for three representative studies (experiments 1,3 , and 14). In the upper portion of the figure are shown the

${ }^{3}$ The respiratory center may have been less responsive to 7 and $11 \%$ carbon dioxide in the reverse protocol either as a result of the somewhat higher plasma bicarbonate (and lower hydrogen ion concentration) or as the consequence of the initial exposure to $18 \%$ carbon dioxide. hydrogen ion concentrations and the calculated weighted regression lines for each experiment. By inspection there appears to be a striking linearity in the $\mathrm{H}^{+} / \mathrm{PCO}_{2}$ relationship. The same linear relationship between hydrogen and $\mathrm{PCO}_{2}$ is demonstrated by all of the twenty-one experiments shown in Table II. This interpretation is supported by the statistical analysis that is described in detail in the Appendix. For the 7-11-18\% group the average slope and intercept of the weighted regression lines were 0.79 (range, .70 to .91 ) and 13.7 (range, 10.7 to 16.6), respectively. For the 11-15-18\% protocol these values were 0.75 (range, .63 to .80 ) and 14.5 (range, 10.4 to 17.2). The differences between these mean slopes and intercepts were not significant, and the overall mean slope and intercept for the fourteen studies were $0.77(\mathrm{SE}=0.02)$ and $14.1(\mathrm{SE}=$ 0.6) (Figure 1). The mean regression line for the reverse protocol is shown in Figure 2. As with the upgoing study, statistical analysis of the individual experiments supports the interpretation that there is a linear relationship between $\mathrm{PCO}_{2}$ and hydrogen. The slope of the mean line is 0.77 $(\mathrm{SE}=0.01)$, and its intercept is $10.6(\mathrm{SE}=$ $0.7)$. The range for slope was 0.73 to 0.81 and 
A
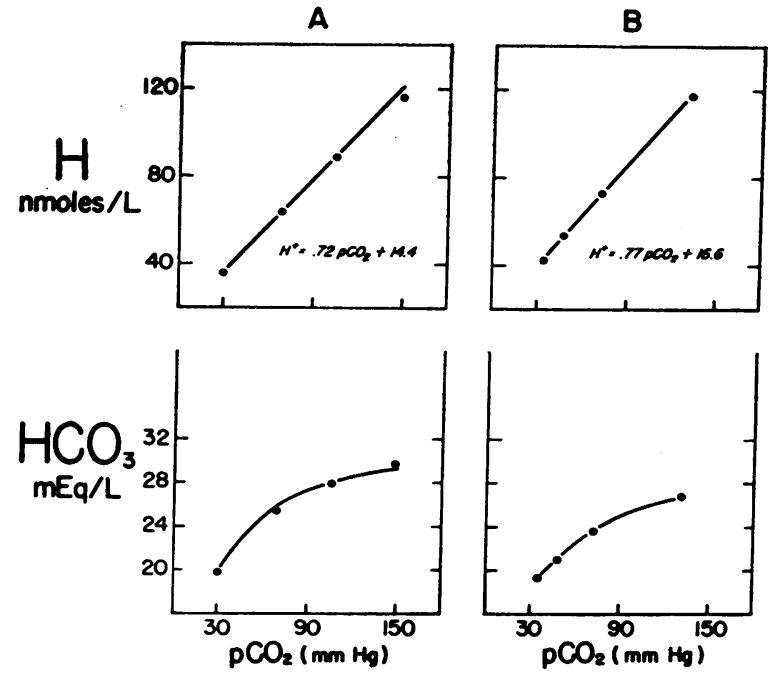

C
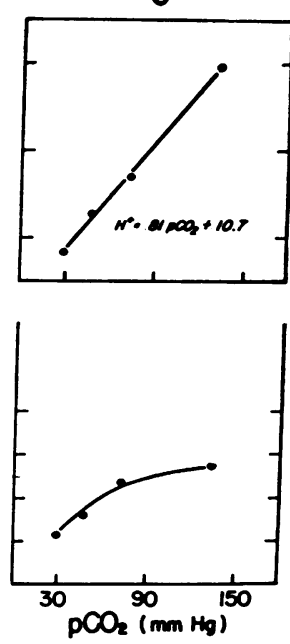

Fig. 3. Plasma hydrogen ion and bicarbonate concentrations related TO $\mathrm{PCO}_{2}$ FOR THREE INDIVIDUAL EXPERIMENTS FROM THE "UPGOING" GROUP (eXperiments 14, 3, and 1, Table II). Each point represents the average of all observations made during the steady state. The weighted regression lines for hydrogen on $\mathrm{PCO}_{2}$ are shown with the corresponding equation. The curves drawn through the bicarbonate values have been obtained by substituting in a modified Henderson equation the slope and intercept of the $\mathrm{H}^{+} / \mathrm{PcO}_{2}$ line for each experiment (see text).

for intercept 8.7 to 14.2. The slope for the reverse protocol is not significantly different from that of the upgoing; however, the intercept was slightly but significantly lower $(p<0.01)$.

The bicarbonate concentrations for each of the three representative experiments are shown in the lower half of Figure 3. The curves drawn through the points have been obtained by substituting in a modified Henderson equation ${ }^{4}$ (15) the slope and intercept shown for each experiment in the upper part of the figure. Similar curves were calculated for all twenty-one experiments; the deviations of the experimental observations from these theoretical lines averaged $\pm 0.5 \mathrm{mEq}$ per $\mathrm{L}$.

Other plasma constituents (Table III). Both sodium and potassium concentrations rose slightly in all three protocols. Phosphate concentration rose progressively with each increment in $\mathrm{PCO}_{2}$;

4 The mass law equation of the carbonic acid-bicarbonate buffer system at equilibrium can be written: $\left[\mathrm{H}^{+}\right]\left[\mathrm{HCO}_{3}^{-}\right] / \alpha \mathrm{Pco}_{2}=\mathrm{K}$. When $\mathrm{K}=7.94 \times 10^{-7}, \alpha=$ 0.0301 , and the units of $\mathrm{H}^{+}, \mathrm{HCO}_{3}^{-}$, and $\mathrm{PCO}_{2}$ are nmoles per $\mathrm{L}, \mathrm{mEq}$ per $\mathrm{L}$, and $\mathrm{mm} \mathrm{Hg}$, respectively ; substitution of the linear regression, $\mathrm{H}^{+}=\mathrm{m}\left(\mathrm{Pco}_{2}\right)+\mathrm{n}$, yields : $\mathrm{HCO}_{3}^{-}=23.9 \mathrm{PCO}_{2} / \mathrm{m}\left(\mathrm{PCO}_{2}\right)+\mathrm{n}$. at $18 \%$ carbon dioxide the concentration was approximately twice the control value. All of these changes during acute hypercapnia have been described previously $(1,4,16-19)$. Chloride concentration showed no significant change. Whole blood lactate and pyruvate levels were determined in five of the experiments in the $7-11-18 \%$ group. Lactate concentration during the control period averaged 2.4 mmoles per $\mathrm{L}$ and pyruvate 0.4 mmoles per $\mathrm{L}$. At the $18 \%$ level the values were significantly lower, 0.6 mmoles per $\mathrm{L}$ for lactate and 0.1 mmoles per $\mathrm{L}$ for pyruvate, a finding similar to that reported previously (1).

In both the upgoing and reverse groups the decrease in extracellular fluid volume calculated from changes in "chloride space" was between 0.1 and $0.2 \mathrm{~L}$ over the 6 -hour period. There was no significant change in concentration of plasma water, which in four experiments averaged 945 $\mathrm{ml}$ per $\mathrm{L}$ before and after the end of the study.

Urine composition. The average urine volume was less than $100 \mathrm{ml}$ during the course of the experimental procedure. Potassium excretion averaged $18 \mathrm{mEq}$, and sodium and chloride each averaged $7 \mathrm{mEq}$ for the 6-hour experimental pe- 
TABLE III

Average plasma electrolyte concentrations during titration of the dog with carbon dioxide

\begin{tabular}{|c|c|c|c|c|c|c|c|c|c|c|c|c|}
\hline & \multicolumn{4}{|c|}{ a. $(7$ dogs $)$} & \multicolumn{4}{|c|}{ b. $(7$ dogs $)$} & \multicolumn{4}{|c|}{ c. $(7$ dogs $)$} \\
\hline & Contro! & $7 \%$ & $11 \%$ & $18 \%$ & Control & $11 \%$ & $15 \%$ & $18 \%$ & Control & $18 \%$ & $11 \%$ & $7 \%$ \\
\hline Sodium, & 145.9 & 146.9 & 149.1 & 151.1 & 146.1 & 149.8 & 151.7 & 152.0 & 147.0 & 150.2 & 150.4 & 149.8 \\
\hline $\begin{array}{l}\text { Potassium, } \\
m E q / L\end{array}$ & 4.3 & 4.4 & 4.4 & 4.5 & 4.2 & 4.3 & 4.6 & 4.7 & 4.1 & 4.6 & 4.6 & 4.4 \\
\hline $\begin{array}{l}\text { Chloride, } \\
m E q / L \\
\text { Bicarbonate, }\end{array}$ & 110.5 & 110.9 & 111.6 & 111.6 & 110.7 & 111.6 & 111.9 & 111.5 & 113.1 & 111.6 & 113.4 & 114.1 \\
\hline $\begin{array}{l}m E q / L \\
\text { Phosphate. }\end{array}$ & 19.9 & 21.7 & 24.5 & 27.1 & 19.6 & 24.6 & 27.3 & 28.8 & 21.3 & 27.5 & 26.6 & 24.7 \\
\hline $\begin{array}{c}\mathrm{mg} / 100 \mathrm{ml} \\
\text { Undetermined }\end{array}$ & 4.0 & 5.6 & 6.8 & 7.4 & 3.7 & 6.2 & 7.1 & 7.4 & 3.7 & 9.0 & 6.2 & 5.0 \\
\hline$m E q / L$ & 19.8 & 18.7 & 17.4 & 16.9 & 20.0 & 17.9 & 17.1 & 16.4 & 16.7 & 15.7 & 15.0 & 15.4 \\
\hline
\end{tabular}

* Undetermined anions $=(\mathrm{Na}+\mathrm{K})-\left(\mathrm{Cl}+\mathrm{HCO}_{3}\right)$.

riod. The mean bicarbonate excretion in the upgoing experiments was $1.1 \mathrm{mEq}$ and in the reverse protocol was $2.9 \mathrm{mEq}$. The net acid excretion averaged 3.8 and $2.7 \mathrm{mEq}$ in the upgoing and reverse groups, respectively.

Whole blood titration. Figure 4 shows the in vitro titration of whole blood with carbon dioxide and compares the results with those obtained from the in vivo, upgoing studies. The plasma bicarbonate concentration in vitro is higher than in the intact organism at every level of $\mathrm{PCO}_{2}$. This difference was significant $(p<0.01)$ at carbon dioxide tensions of $70 \mathrm{~mm} \mathrm{Hg}$ and above. A comparison of the in vitro curve with the curve obtained from the reverse experiments reveals a similar discrepancy.

\section{Discussion}

This study serves to define the nature of the whole body carbon dioxide titration curve in the unanesthetized dog under conditions in which the kidney makes no significant contribution to the buffer response. The data indicate that degrees of hypercapnia induce a curvilinear rise in extracellular bicarbonate concentration, the increment in bicarbonate diminishing as $\mathrm{PCO}_{2}$ is elevated. When the response to hypercapnia is expressed in terms of change in hydrogen ion concentration, a quite different pattern emerges. The regression of hydrogen on $\mathrm{PCO}_{2}$ demonstrates a striking linearity both by inspection (Figure 3 ) and upon statistical analysis (see Appendix).
The deviation of observed hydrogen ion concentration about the individual regression lines averaged no more than 2 nmoles per L. Thus, over a wide range of acutely induced changes in carbon dioxide tension, extracellular hydrogen ion concentration is defended with a virtually constant degree of effectiveness.

Although each animal displayed a linear relationship between hydrogen ion concentration and $\mathrm{PCO}_{2}$, there was considerable variation in the slope and intercept of the individual lines. This is in part accounted for by differences in the initial plasma bicarbonate concentrations but is also a function of quantity of bicarbonate generated by each animal.

The explanation for the observed linearity between $\mathrm{H}^{+}$and $\mathrm{PCO}_{2}$ is obscure. Titration of a buffer mixture over a narrow range of hydrogen ion concentrations could produce such a pattern; whole blood, for example, yields a straight line relationship over a hydrogen ion concentration as wide as that examined here $(20-23)$. The situation in vivo, however, is more complicated, since bicarbonate is generated not only by buffers in the extracellular fluid but also (and to an even larger extent) by sources outside this compartment (1). The linear $\mathrm{H}^{+} / \mathrm{PCO}_{2}$ relationship would, therefore, appear to depend on the appropriate delivery of bicarbonate to the extracellular fluid. Our data throw no light on the mechanism that might govern such a transfer. Regardless of the factors governing the $\mathrm{H}^{+} / \mathrm{PCO}_{2}$ relationship, the observed pattern may well provide a basis for detecting al- 


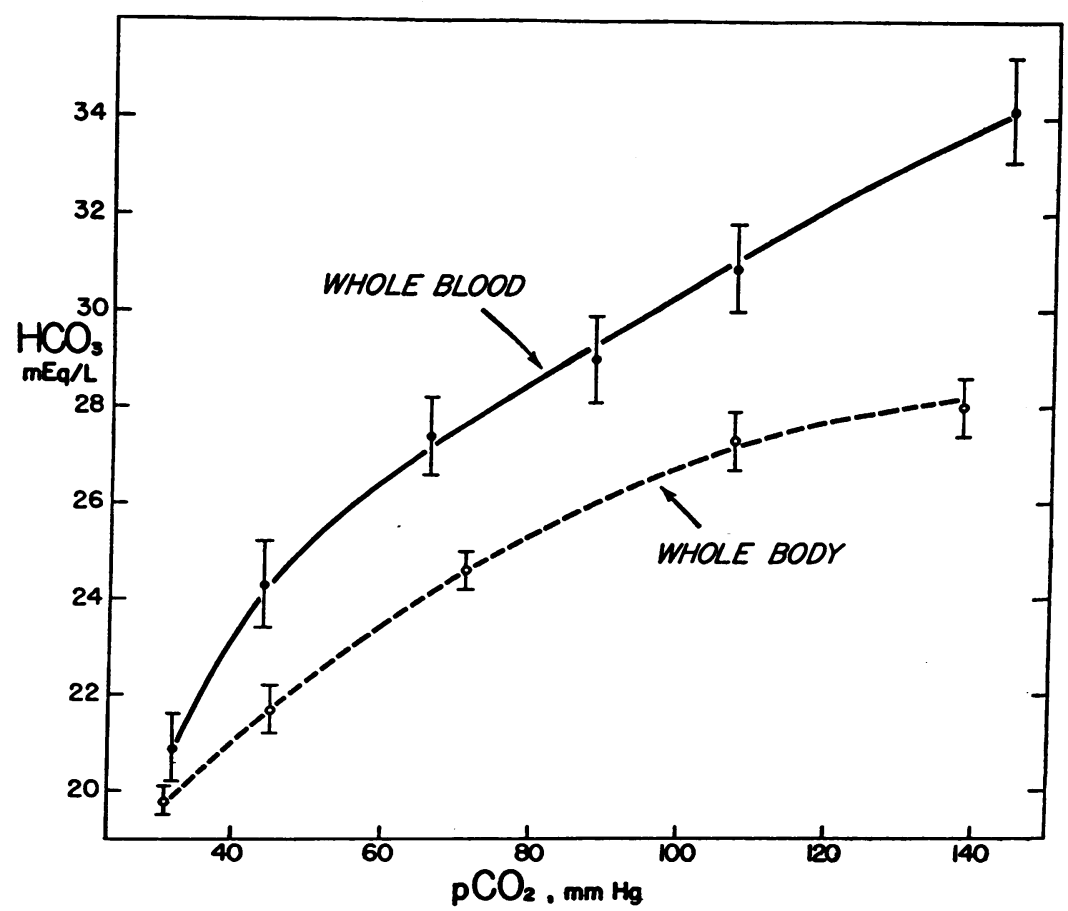

Fig. 4. COMParison OF THE CARBON DIOXIDE TItration CURVES FOR WHOLE BLOOD AND WHOLE BODY. The whole body data were obtained from the upgoing studies. Whole blood curves represent the average of eleven in vitro titrations. The bicarbonate concentrations are significantly different $(p<0.01)$ at carbon dioxide tensions of $70 \mathrm{~mm} \mathrm{Hg}$ and above. Ranges shown around each mean point represent \pm one $\mathrm{SE}$.

terations in buffer characteristics of the organism that might be induced by a variety of experimental conditions. By virtue of the small standard errors of the mean slope and intercept, it should be possible to determine by titration of the intact organism whether the appearance of bicarbonate in the extracellular fluid has been significantly modified by such factors as drugs, potassium depletion, or metabolic acid-base disturbances.

These considerations regarding the buffer contribution of tissues are also pertinent to recent statements that metabolic acidosis is a regular concomitant of respiratory acidosis $(4,5,24-27)$. This interpretation has been based solely on indirect measurements (i.e., "standard bicarbonate" and "whole blood buffer base"), and no evidence of fixed acid accumulation in the extracellular fluid has been adduced. Our observations demonstrate that a significant element of metabolic acidosis does not occur even with severe hypercapnia. The normal blood lactate and pyruvate concen- trations and the persistently normal values for unmeasured anions indicate that metabolic acids could not have accumulated in significant quantity in the extracellular fluid. Previous interpretations concerning a complicating metabolic acidosis have rested on the assumption than any deviation of plasma bicarbonate concentration in the intact organism from that predicted by in vitro titration of whole blood defines the presence of a nonrespiratory acid-base disturbance $(4,28)$. This view presupposes that the titration curve of blood and whole body will be identical, a concept for which there is no a priori basis (29). As shown in Figure 4, whole body titration with carbon dioxide between 30 and $140 \mathrm{~mm} \mathrm{Hg}$ produces a smaller rise in plasma bicarbonate concentration than does the titration of whole blood, the difference becoming substantial above $70 \mathrm{~mm} \mathrm{Hg}$. These observations suggest that with severe, acute hypercapnia the tissue contribution of bicarbonate is insufficient to elevate the bicarbonate concentra- 
tion of interstitial fluid by the amount that blood buffers elevate the plasma concentration; this, in turn, allows the diffusion of bicarbonate from plasma to interstitial fluid and accounts for the difference between the in vitro and in vivo titration curves. A similar analysis based on the response of the dog to $10 \%$ carbon dioxide was presented many years ago by Shaw and Messer (30).

The whole body titration curves from the upgoing studies (Figures 1 and 4 ) are similar to those obtained from the reverse experiments (Figure 2). The slopes of the mean $\mathrm{H}^{+} / \mathrm{PCO}_{2}$ relationships are in fact identical, and the intercepts are only slightly different. The explanation for the slightly higher bicarbonate concentrations at the intermediate points in the reverse study is not clear. This finding might be attributed to slight dehydration, but several observations in hydrated dogs have demonstrated that maintaining body weight and extracellular volume (calculated from "chloride space") does not influence the shape of the upgoing response curve. The possibility that a slowly equilibrating buffer compartment might have contributed to this difference cannot be excluded and is suggested by the slight rise in bicarbonate found in the preliminary plateau studies. In any event the similarity between the upgoing and reverse curves suggests that any rise in bicarbonate concentration that might have occurred during the 6-hour titration studies in excess of that resulting from the immediate response to the elevations of $\mathrm{PCO}_{2}$ did not materially influence the pattern of response.

Morris and Millar (5), in a recent study of the catecholamine response to hypercapnia, obtained data from which $\mathrm{HCO}_{3}{ }^{-} / \mathrm{PCO}_{2}$ and $\mathrm{H}^{+} / \mathrm{PCO}_{2}$ curves can be derived. Although the experimental conditions (general anesthesia, mechanical ventilation, and 15 minutes of exposure to each level of carbon dioxide) were quite different from those of our study, the curves are closely similar. Furthermore, this similarity suggests that a close approximation of an acute steady state can be achieved even with a very brief period of exposure.

In our studies no attempt has been made to evaluate intracellular acid-base changes with increasing degrees of hypercapnia. However, studies of the rat diaphragm in vitro using DMO (5,5-dimethyl-2,4-oxazolidinedione) have demon- strated a pattern of response within cells that is quite different from that observed in the extracellular fluid of the dog (31); hydrogen ion concentration was virtually unchanged by mild or moderate increases in carbon dioxide tension, intracellular acidosis developing only when $\mathrm{PCO}_{2}$ exceeded $70 \mathrm{~mm} \mathrm{Hg}$. It would be of interest to determine if a similar pattern of response occurs in muscle in vivo and to explore the relationship between intra- and extracellular hydrogen ion concentrations during whole body titration with carbon dioxide.

\section{Summary}

Acute changes in extracellular fluid composition have been studied in unanesthetized dogs subjected to whole body titration with carbon dioxide. Each animal was exposed over a 6-hour period to three concentrations of carbon dioxide that produced arterial carbon dioxide tensions ranging from approximately 30 to $140 \mathrm{~mm} \mathrm{Hg}$. The data demonstrate that increasing degrees of hypercapnia induce a curvilinear rise in extracellular bicarbonate concentration, the increment in bicarbonate diminishing as $\mathrm{PcO}_{2}$ is elevated.

On the other hand, changes in $\mathrm{PCO}_{2}$ induced linear changes in hydrogen ion concentration over the entire range of carbon dioxide tensions studied. The mean increase in $\mathrm{H}^{+}$was 0.77 nmoles per $\mathrm{L}$ for every millimeter increment in $\mathrm{PCO}_{2}$. Reversing the sequence of exposure, i.e., beginning the experiment with the most severe degree of hypercapnia, did not alter this relationship. We suggest that whole body titration with carbon dioxide may provide a useful means for detecting experimentally induced changes in whole body buffer characteristics.

\section{Acknowledgments}

The authors wish to thank Mr. Robert Berk for his valuable assistance in the statistical analysis of the data. The determinations of blood lactate and pyruvate were kindly performed in the laboratories of Dr. William E. Huckabee.

\section{Statistical Appendix}

Calculation of Linear Regression of $\mathrm{H}^{+}$on $\mathrm{PCO}_{2}$

As a preliminary to assessing the goodness of fit of a linear relationship between $\mathrm{H}^{+}$and $\mathrm{PCO}_{2}$, the homogeneity 
of variance among animals was examined. A separate analysis was made at each of the five levels of $\mathrm{CO}_{2}$ studied $(0,7,11,15,18 \%)$, employing the ratio of the largest variance to the sum of the variances (32). ( Two determinations of $\mathrm{H}^{+}$concentration were available during the control period and three at each level of hypercapnia.) The results of this analysis demonstrated that, whereas the variances were homogeneous at a single $\mathrm{CO}_{2}$ level, 5 they were not homogeneous from level to level, increasing with the degree of hypercapnia.

The hydrogen ion values for a given animal were then grouped around the mean arterial $\mathrm{PCo}_{2}$ for the four levels of inspired carbon dioxide (including the control) employed in a given study. A weighted linear regression of $\mathrm{H}^{+}$on $\mathrm{PCO}_{2}$ was next calculated separately for each animal. The weight employed at each level of $\mathrm{CO}_{2}$ was the reciprocal of the average estimated variance at that level. The estimate for the control period had 21 degrees of freedom and for each level of hypercapnia had over 40 degrees of freedom.

Because multiple observations were available at each level, an "F" test could then be performed to evaluate the goodness of fit of each of these lines. In most cases deviations from linearity were not significant. Seventeen of the " $F$ " ratios had associated $p$ values greater than 0.01 and 14 of these greater than 0.05 . Moreover, the percentage of variation explained by the linear fit (beyond that explained by the mean) was over $99 \%$ in twenty experiments and $98 \%$ in the one remaining experiment.

Mean regressions were computed for the seven experiments in each protocol by averaging the individual slopes and intercepts. When $t$ tests were then performed in a pair-wise manner on the average slopes, they revealed no significant differences among the three protocols. Similar tests of the average intercepts revealed a significant difference $(p<0.01)$ between the "reverse" protocol and each of the two "upgoing" protocols.

\section{References}

1. Giebisch, G., L. Berger, and R. F. Pitts. The extrarenal response to acute acid-base disturbances of respiratory origin. J. clin. Invest. 1955, 34, 231.

2. Polak, A., G. D. Haynie, R. M. Hays, and W. B. Schwartz. Effects of chronic hypercapnia on electrolyte and acid-base equilibrium. I. Adaptation. J. clin. Invest. 1961, 40, 1223.

3. Andersen, O. S. Acute experimental acid-base disturbances in dogs. Scand. J. clin. Lab. Invest. 1962, 14 (suppl. 66).

4. Brown, E. B., Jr. Plasma electrolyte composition in dogs breathing high $\mathrm{CO}_{2}$ mixtures: source of bicarbonate deficit in severe respiratory acidosis. J. Lab. clin. Med. 1960, 55, 767.

5. Morris, M. E., and R. A. Millar. Blood pH/plasma catecholamine relationships: respiratory acidosis. Brit. J. Anaesth. 1962, 34, 672.

${ }^{5} \mathrm{~A}$ single outlier variance was found (at $11 \% \mathrm{CO}_{2}$ ); this value was rejected.
6. Schwartz, W. B., and L. Silverman. In preparation.

7. Sanderson, P. H. Potentiometric determination of chloride in biological fluids. Biochem. J. 1952, 52, 502.

8. Barker, S. B., and W. H. Summerson. The colorimetric determination of lactic acid in biological material. J. biol. Chem. 1941, 138, 535.

9. Friedmann, T. E., and G. E. Haugen. Pyruvic acid. II. The determination of keto acids in blood and urine. J. biol. Chem. 1943, 147, 415.

10. Kingsley, G. R. The direct biuret method for the determination of serum proteins as applied to photoelectric and visual colorimetry. J. Lab. clin. Med. 1942, 27, 840.

11. Wolfson, W. Q., C. Cohn, E. Calvary, and F. Ichiba. Studies in serum proteins. Amer. J. clin. Path. 1948, 18, 723.

12. Albrink, M. J., P. M. Hald, E. B. Man, and J. P. Peters. The displacement of serum water by the lipids of hyperlipemic serum. A new method for the rapid determination of serum water. J. clin. Invest. 1955, 34, 1483.

13. Atkins, E. L., and W. B. Schwartz. Factors governing correction of the alkalosis associated with potassium deficiency; the critical role of chloride in the recovery process. J. clin. Invest. 1962, 41, 218.

14. Andersen, O. S., K. Engel, K. Jørgensen, and P. Astrup. A micro method for determination of $\mathrm{pH}$, carbon dioxide tension, base excess and standard bicarbonate in capillary blood. Scand. J. clin. Lab. Invest. 1960, 12, 172.

15. Henderson, L. J. The theory of neutrality regulation in the animal organism. Amer. J. Physiol. 1908, 21, 427.

16. Scribner, B. H., K. Fremont-Smith, and J. M. Burnell. The effect of acute respiratory acidosis on the internal equilibrium of potassium. J. clin. Invest. $1955,34,1276$.

17. Elkinton, J. R., R. B. Singer, E. S. Barker, and J. K. Clark. Effects in man of acute experimental respiratory alkalosis and acidosis on ionic transfers in the total body fluids. J. clin. Invest. 1955, 34, 1671.

18. Fenn, W. O., and T. Asano. Effects of carbon dioxide inhalation on potassium liberation from the liver. Amer. J. Physiol. 1956, 185, 567.

19. Haldane, J. B. S., V. B. Wigglesworth, and C. E. Woodrow. The effect of reaction changes on human inorganic metabolism. Proc. roy. Soc. B 1924, 96, 1.

20. Peters, J. P. Studies of the carbon dioxide absorption curve of human blood. III. A further discussion of the form of the absorption curve plotted logarithmically, with a convenient type of interpolation chart. J. biol. Chem. 1923, 56, 745.

21. Brewin, E. G., R. P. Gould, F. S. Nashat, and E. Neil. An investigation of problems of acid-base equilibrium in hypothermia. Guy's Hosp. Rep. $1955,104,177$. 
22. Jørgensen, K., and P. Astrup. Standard bicarbonate, its clinical significance and a new method for its determination. Scand. J. clin. Lab. Invest. 1957, 9, 122.

23. Holmdahl, M. H. Pulmonary uptake of oxygen, acid-base metabolism, and circulation during prolonged apnoea. Acta chir. scand. 1956, (suppl. 212).

24. Holaday, D. A., D. Ma, and E. M. Papper. The immediate effects of respiratory depression on acidbase balance in anesthetized man. J. clin. Invest. 1957, 36, 1121.

25. Joels, N., and M. Samueloff. Metabolic acidosis in diffusion respiration. J. Physiol. 1956, 133, 347.

26. Frumin, M. J., R. M. Epstein, and G. Cohen. Apneic oxygenation in man. Anesthesiology 1959, 20, 789.

27. Cunningham, D. J. C., B. B. Lloyd, and C. C. Michel. Acid-base changes in the blood during hypercapnia and hypocapnia in normal man. J. Physiol. 1962, 161, 26P.
28. Singer, R., and A. B. Hastings. An improved clinical method for the estimation of disturbances of the acid-base balance of human blood. Medicine 1948, 27, 223.

29. Schwartz, W. B., and A. S. Relman. A critique of the parameters used in the evaluation of acid-base disorders. New Engl. J. Med. 1963, 268, 1382.

30. Shaw, L. A., and A. C. Messer. The transfer of bicarbonate between the blood and tissues caused by alterations of the carbon dioxide concentration in the lungs. Amer. J. Physiol. 1932, 100, 122.

31. Relman, A. S., S. Adler, and A. Roy. Intracellular acid-base equilibrium: the reaction of muscle cells to "metabolic" and "respiratory" changes in extracellular acidity. Trans. Ass. Amer. Phycns 1963, 76, 176.

32. Cochran, W. G. The distribution of the largest of a set of estimated variances as a function of their total. Ann. Eugen. (Lond.) 1941, 11, 47.

\section{SPECIAL NOTICE TO SUBSCRIBERS}

Post Offices will no longer forward the Journal when you move.

Please notify The Journal of Clinical Investigation, Business Office, 10 Stoughton Street, Boston 18, Mass., at once when you have a change of address, and do not omit the Zip Code number if there is one. 